\title{
A NEW DESIGN METHOD FOR LOW-SPEED TORUS TYPE AFPM MACHINE FOR HEV APPLICATIONS
}

\author{
Hojat Hatami $^{1}$, Mohammad Bagher Bannae Sharifian ${ }^{2}$, Mehran Sabahi ${ }^{3}$ \\ 1, 2, 3 Faculty of Electrical \& Computer Engineering, University of Tabriz, Tabriz, Iran \\ h-hatami@tabrizu.ac.ir, sharifian@tabrizu.ac.ir, sabahi@tabrizu.ac.ir
}

\begin{abstract}
Axial flux permanent magnet (AFPM) machine type has some advantages such as compressed packaging, easy handling, and safety operation. In this paper the proper structure selection of AFPM machine for hybrid electric vehicle (HEV) application is one of the aims. To reduce the losses and the total volume of machine, the coreless TORUS-NS type machine is selected. Designing of this machine, to obtain a wide speed range with high efficiency, low cogging torque and high torque value, as in-wheel direct-drive AFPM machine for HEV, is investigated. The operation performance in low and medium speed ranges is studied. A new design method based on multi speed design (MSD) strategy is proposed. Using this method with a coreless type of stators, the total AFPM machine efficiency at the HEV operation cycles could be improved. Performance analysis of this in-wheel AFPM machine is done using finiteelement method (FEM). FEM analysis of the single-speed design (SSD) method is also done. MSD and SSD designed machines are applied in HEV and simulated using urban and highway cycles. The obtained results show the better performance of HEV, using the MSD based designed machine in all operation cycles. The experimental results obtained from sample practical prototype, confirm the analytical method.
\end{abstract}

Keywords: Hybrid electric vehicles (HEV), axial flux permanent magnet (AFPM), TORUS type, direct-drive, in-wheel, multi-speed design, single-speed design.

\section{INTRODUCTION}

The anxieties about the world petrol, gas reserves and their prices, as well as pollution and global warming issues, have increased the interest on electric and hybrid vehicles. The HEVs on the market today are primarily parallel hybrids in which the drive power for the vehicle is supplied by both an internal combustion engine (ICE) and a set of electric machines $[1,2]$. A different system design is the series HEV. In this type, the ICE is disconnected from the drive-train and the electric machines provide all drive power to the vehicle wheels.

Permanent magnet (PM) machines have been widely used for electric vehicle (EV) and HEV applications. This is due to having inherently more efficiency than other electric machines because of their PM excitation. An axial flux PM machine (AFPM) benefits such as simplified construction, their compact design, high power density, high efficiency, superior torque density, possibility to add a high number of poles, very low rotor losses and adjustable axial air gap, produces a machine that is efficient and compact and is therefore ideally suited for use in vehicle [9]. Also a coreless type of stators can help to improve the total machine efficiency as a result of power loss reduction [2-4]. Moreover, due to its inherently short axial length, it is suitable for the electric traction machine as in-wheel direct-drive motor. In the direct-drive traction system, mechanical power transmission compartments are eliminated and therefore the volume and weight of the whole drive system is reduced as well as the transmission losses are minimized. Furthermore the drive system is simplified and its operation efficiency is improved. So it can be said using in-wheel motor for direct drive instead of conventional motor drive with mechanical power transmission gears, is the future direction of motor drive system for HEVs. There is no mechanical transmission system between the wheel and electric motor in such a direct-drive power train system, and electric machine is directly connected and coupled to the wheel, therefore electric machine and wheel have the same torque and speed $[5,6]$.

If the number of poles in the AFPM machines is large enough and the axial length sufficiently small, their torque density is considerably larger than that obtained by traditional radial flux (RF) machines [1]. Moreover, due to the relatively small speed of the wheels, with a large number of poles, using AFPM machine as a gearless in-wheel drive is feasible [7-10]. In addition high torque density and high efficiency are necessary for a vehicle with an in-wheel direct-drive system and also such vehicle propulsion system requires low cogging torque and wide range of constant power speed. These issues need to be considered during the design procedure of the AFPM 
machines for the direct drive HEV application as in-wheel machines.

In this paper, a novel designed low-speed coreless AFPM machine for an in-wheel gearless drive of HEV is proposed and the analytical design procedure to achieve high efficiency at the vehicle's various speeds is presented. The AFPM has a three-phase winding which can produce a rotary magnetic field in the air gap. This type of electric machine can provide high-power density at low speed and, hence, it is acceptable to use as a direct drive in HEVs [10, 11]. Both analytical and quasi three-dimensional electromagnetic finite element analysis (Q-3D FEA) models are employed to calculate the parameters of the machine. Moreover, the FEA is used to further analyses and optimize the machine performance and the experimental results obtained from sample practical prototype, confirm the analytical method.

\section{CONFIGURATION OF AFPM MACHINE}

Flux in an axial flux machine flows through the air-gap axially. AFPM machines have discs for the rotor and the stator geometry. There are some different structures for AFPM machines due to the various applications: one rotor and one stator (Fig. 1-a), stator between two rotors (TORUS type) (Fig. 1-b), rotor between two stators (AFIPM type) (Fig. 1-c), and Multi-disc structure including several rotors and stators (Fig. 1-d).

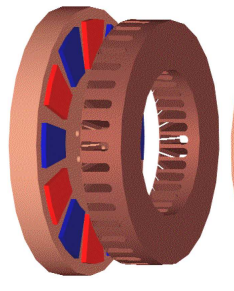

(a)

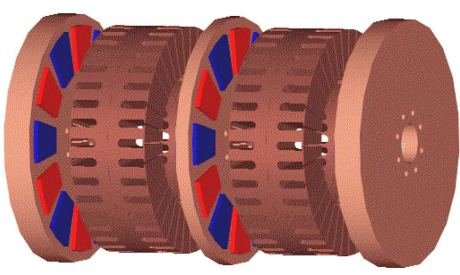

(b)
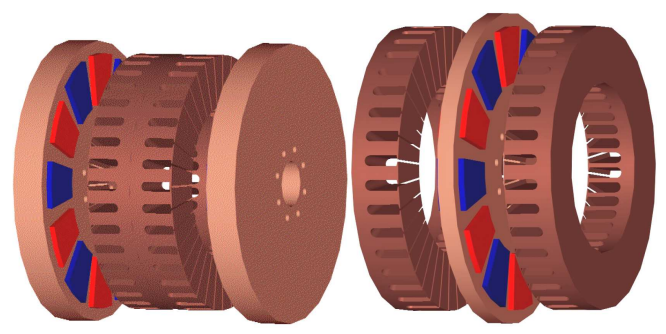

(c)

(d)

Fig 1 Different structures for AFPM machines, a) Structure with one rotor and one stator, b) Multi-disc structure, c) TORUS type, and d) AFIPM type.
In the single-rotor - single-stator structure due to an unbalanced axial force between the rotor and the stator discs more complex bearing arrangements and a thicker rotor disk are needed. Such problem is not seen in the other configurations. Two configurations are presented in the TORUS case of AFPM machines. The type of PM arrangements on the two exterior rotor discs has an effect on the main flux path in the machine. In the case of north-north arrangement (TORUS-NN) as shown if fig. 2-a, the main flux has to flow circumferentially along the stator core and then a thick stator yoke is needed. Therefore iron losses and the end winding lengths increase. In the case of north-south structure (TORUS-NS) (fig. 2-b) the main flux flows axially through the stator, thus the structure does not need a stator yoke at all. Moreover if the non-slotted stator (i.e. without iron yoke) is used in the TORUS-NS structure, iron losses is decreased and cogging torque is minimized at the motoring application. To produce useful torque at this machine type the lap windings need to be used in the structure.

In a single rotor- two stators structure, the PMs may be located on a surface of the rotor disk. In the other configuration the magnets may be buried into the rotor disk. Thereby, the main flux path in the rotor disk may be axially or circumferentially. The surface-mounted structure has a very thin rotor. This object is very palpable when a non-ferromagnetic rotor core is used. In the other structure in which the permanent magnets are located inside the rotor disk, rotor is much thicker. This reduces the power density of the machine. The multistage configuration has the much axial length as compared to other types of AFPM machines that leads to be unsuitable choice for some application such as in-wheel vehicular application.

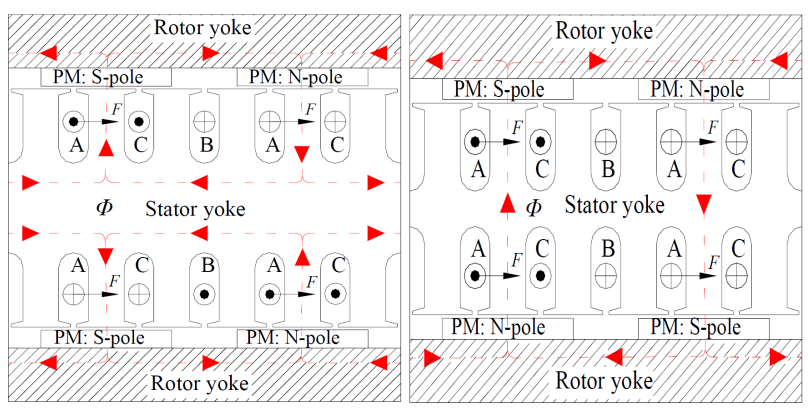

(a)

(b)

Fig 2 Cross sectional view of a, a) TORUS-NN and b) TORUS-NS types AFPM machine

In this paper the proposed AFPM is supposed to be placed inside the wheel and used as a direct drive machine. Therefore the axial length of the machine should be small as possible. Moreover to achieve the highest efficiency, the amount of losses need be kept low. At the vehicle driving cycle, the desired machine may be used as a motor. The best 
characteristic in the motoring mode is the cogging-less condition. The cogging torque is due to the effects of slotting in the stator. In the ironless stator the slotting effect tends toward zero. With this interpretation the best choice to achieve these objectives in the vehicle as an axial flux PM in-wheel machine configuration is TORUS-NS type with an ironless stator. This AFPM machine has the configuration with two rotors and one coreless (ironless) stator. The stator core is made by epoxy resin and windings are inserted in the stator core. The stator has a set of three-phase AC windings. Owing to produce useful torque and to generate nearly sinusoidal output voltage (when using as a generator as needed) in this structure, distributed armature coils are employed.

In the surface mounted AFPM motor, PMs are glued to the surfaces of solid mild steel rotor disc. The best candidate for the permanent magnets in the rotors is sintered neodymiumiron-boron (Nd-Fe-B) material. With the large air gap the synchronous reactance also will be low. Due to the absence of core losses in the stator, the efficiency will be high. Coreless AFPM machines are also used for various power and torque generation applications, particularly in direct-drives systems over a wide range of operational speed. These types of machines are examined for low- and medium-speed applications such as wind turbine generators and applications for vehicular generators. The rotor copper loss is minimized due to the using permanent-magnet instead winding excitation.

\section{ANALYTICAL QUASI-3D MODELLING}

In this method to reduce the computation time and to obtain the model with acceptable accuracy the 3D geometry of an AFPM machine is transformed to a corresponding 2D model. In the first step the computation planes is selected as shown in fig 3-a. In this case only one computation plane, with thickness $\mathrm{d} r$, is selected at the average radius of the axial-flux machine. In the second step the selected computation plane is presented as a 2D model of which depth is $\mathrm{d} r$ (fig 3-b). The cross-section of the computation planes in the TORUS machines is shown in fig 3-c and 3-d.

Concerning the quasi-3D modeling, the axial-flux PM machine may be considered to be composed of several axialflux machines with differential radial length. The overall performance of an axial-flux machine is obtained by summing the performances of individual machines and neglecting the possible flux flow in the depth direction of the machine. This approach allows the consideration of different magnet shapes and variations of the teeth width in the direction of the machine radius.

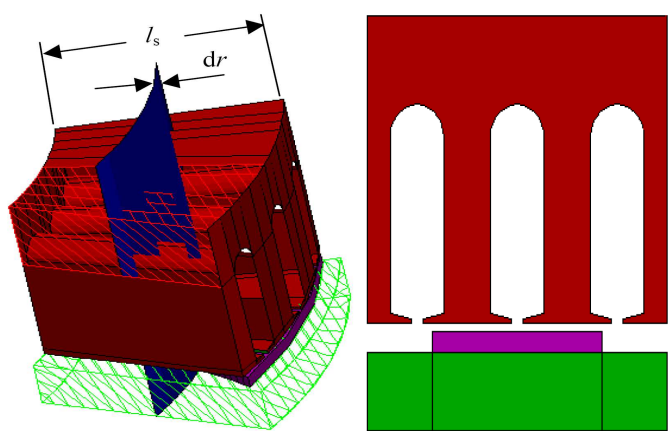

(a)

(b)

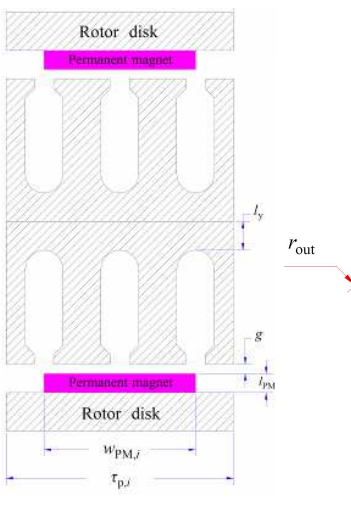

(c)

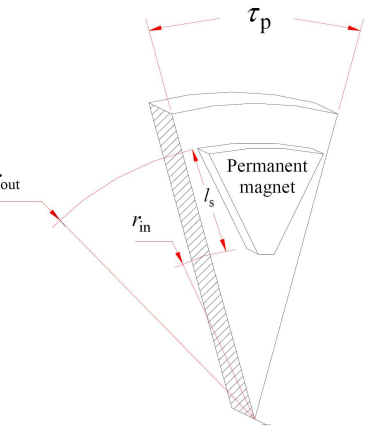

(d)
Fig 3 Method of transforming the 3D geometry of an axialflux machine to a $2 \mathrm{D}$ geometry, a) computation planes, b) the 2D model of the selected plane, c) The cross-section of the computation planes in the TORUS machines and, d) the specifications of the cross section

For the quasi-3D computation, the average diameter $D_{\text {ave }}$ of a particular computation plane $i$, starting from the outer diameter of the machine is given by the equation (1):

$$
D_{\text {ave }, \mathrm{i}}=D_{\text {out }}-j \frac{l_{\mathrm{s}}}{N}
$$

Where $D_{\text {out }}$ is the external diameter of the stator, $N$ is the number of computation planes used in a computation and $l_{\mathrm{s}}$ is the length of the stator stack in meters.

The parameter $j$ in (1) is defined as

$$
j=2 i-1
$$

Where index $i$ goes from 1 to $N$. The length of the stator stack $l_{\mathrm{s}}$ is defined as 


$$
l_{\mathrm{s}}=\frac{D_{\mathrm{out}}-D_{\text {in }}}{2}
$$

Where $D_{\text {in }}$ is the internal diameter of the axial-flux machine stator

The pole pitch $\tau_{\mathrm{p}}$ for each computation plane is given by the equation (4)

$$
\tau_{\mathrm{p}, \mathrm{i}}=\frac{\pi D_{\mathrm{ave}, \mathrm{i}}}{2 p}
$$

Where $p$ is the number of pole pairs.

In general, the relative magnet width $\alpha_{\mathrm{p}}$ may vary along with the machine radius. It is defined as

$$
\alpha_{\mathrm{p}, \mathrm{i}}=\frac{w_{\mathrm{PM}, \mathrm{i}}}{\tau_{\mathrm{p}, \mathrm{i}}}
$$

Where $w_{\mathrm{PM}, \mathrm{i}}$ is the width of the magnet at the computation plane $i$ according to fig. 3 .

Based on the equations (1)-(5) it is possible to divide the machine into a certain amount of computation planes. The number of computation planes needed for computation depends on the purpose of the computation. In the simplest case when the magnet relative width is a constant and the stator is not skewed, basically only one computation plane is required, e.g. to calculate the induced voltage or cogging torque. But, because of the non-linear behavior of the iron losses, to find iron losses, in the iron cored stators, one computation plane is not necessarily sufficient. In this case the coreless type stator is used to eliminate non-linearity effect. Generally, the amount of required computation planes is casedependent.

The computations of the motor parameters, such as the phase resistances, inductances and load angle, can be obtained by using classical electrical machine design methods [19, 20]. When geometry of the axial-flux machine is an inherent 3D problem, the computation of the machine parameters can be based on the average radius $r_{\text {ave }}$ as a design plane since the considered parameters vary linearly with respect to the machine radius or totally independent of the radius.

\section{PERFORMANCE ANALYSIS}

\subsection{Torque Production}

Considering an idealized axial-flux machine structure with double air-gaps, according to fig. 4-a, the expression for the electromagnetic torque produced by the machine may be derived [21]. Fig. 4-b and 4-c show the 3D disassembled and assembled view of the half of the structure of medium-speed coreless surface mounted AFPM motor. In the analysis, it is assumed that the permanent magnets produce a square wave flux density distribution into the air-gap with maximum value $B_{\max }$,

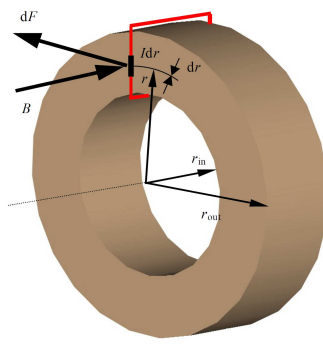

(a)

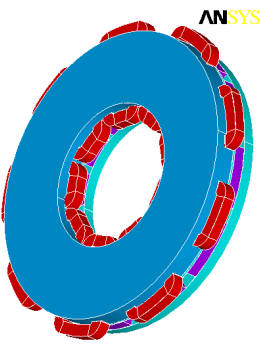

(b)

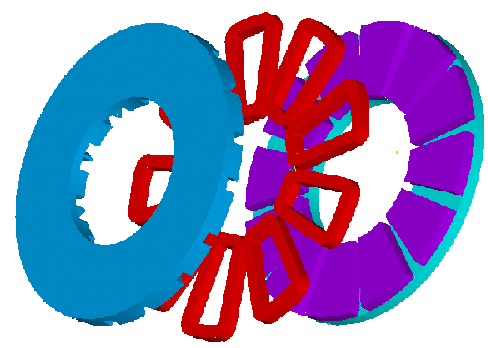

(c)

Fig 4 a) Idealized structure, b) assembled and, c) disassembled view of half of TORUS type AFPM

The winding conductors carry constant current with RMS value $I$, and the current is appropriately timed and perpendicularly oriented with the flux density distribution in the air-gaps. The conductors are located as closely together as possible on the inner radius of the stator core $r_{\text {in }}$. Therefore, the linear current density $A$ on radius $r$ can be written as

$$
A(r)=\frac{A_{\text {in }} r_{\text {in }}}{r}
$$

Where $A_{\text {in }}$ is the linear current density on the inner radius $r_{\text {in }}$ of the machine and is defined as

$$
A_{\text {in }}=\frac{m N_{\mathrm{ph}} I}{\pi r_{\text {in }}}
$$

where $m$ is the number of phases and $N_{\mathrm{ph}}$ is the number of coil turns in series per stator phase winding. 
The machine torque can be calculated from the elementary forces $\mathrm{d} F$ acting on the surface of the stator core. The elementary torque component $\mathrm{d} T_{\mathrm{em}}$ on radius $r$ takes the form

$$
\mathrm{d} T_{\mathrm{em}}=2 \pi r_{\text {in }} A_{\text {in }} B_{\text {max }} r \mathrm{~d} r
$$

Integrating (8) over the machine radius gives the electromagnetic torque for the ideal double sided axial-flux machine

$$
\begin{aligned}
& T_{\mathrm{em}}=2 \pi B_{\text {max }} A_{\text {in }} 2 \int_{r_{\text {in }}}^{r_{\text {out }}} r_{\text {in }} r \mathrm{~d} r \\
& =2 \pi B_{\text {max }} A_{\text {in }} r_{\text {out }}^{3} k_{\mathrm{D}}\left(1-k_{\mathrm{D}}^{2}\right)
\end{aligned}
$$

where $k_{\mathrm{D}}$ is the diameter ratio and is defined as

$$
k_{\mathrm{D}}=\frac{r_{\text {in }}}{r_{\text {out }}}
$$

The electromagnetic torque produced by a real machine is somewhat reduced due to the actual distribution of the flux density in the air-gaps and in the current waveform. However, from equation (10) it is possible to derive the optimal diameter ratio for the maximum electromagnetic torque (equation (9)), in the idealized axial-flux machine, which is [21]

$$
k_{\mathrm{D},{ }_{\mathrm{opt}}}=\frac{1}{\sqrt{3}} \approx 0.58
$$

As axial-flux machines are concerned, the diameter ratio is an important design parameter. The torque production capability of the machine, as a function of $k_{\mathrm{D}}$, is described in fig. 5. The curve is scaled for the maximum torque to be equal to value 1 . Using diameter ratios lower than 0.6 involves practical difficulties, especially in small machines with lap windings. This problem is related to the limited space available between the stator core and the shaft. In small machines it may be very difficult to obtain enough free space between the shaft and the stator core for the end-windings to arrange properly.

This problem can be avoided by using a TORUS type machine, which has its phase winding wound around the stator core. An alternative solution is to obtain the phase winding through concentrated windings. Essentially shorter endwindings in the radial direction are obtained on both the inner radius and outer radius of the stator core.

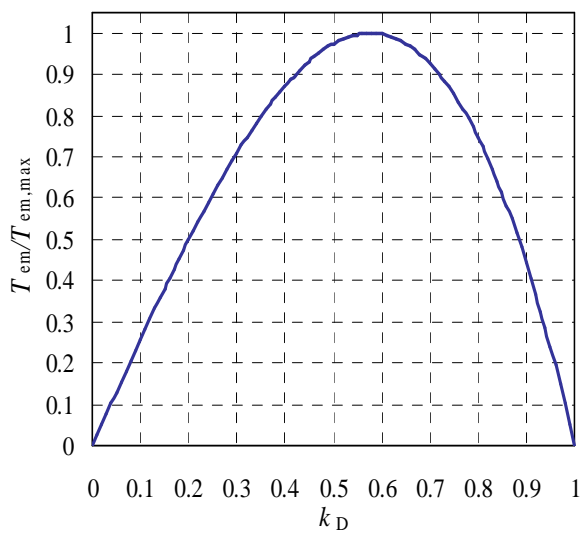

Fig 5.Normalized electromagnetic torque $\left(T_{\mathrm{em}} / T_{\mathrm{em}, \max }\right)$ vs. diameter ratio $k_{\mathrm{D}}$

The tooth width in the iron cored machines is the second problem. From the viewpoint of machine design, it is advantageous when the slot width is a constant. Small diameter ratios may cause the outer radius of the tooth width become very large whereas the inner radius remains very narrow. A narrow tooth appears to be mechanically fragile and it may be excessively saturated on inner radius. In the coreless type there is no saturation problem. It has been shown that the machine torque density reaches its maximum value when the diameter ratio is between 0.6 and 0.65 [22, 23]. Considering the previously discussed mechanical considerations in relation with the torque density characteristic of the axial-flux machine, it is correct to conclude that the practical optimum for the diameter ratio lies between 0.6 and 0.7. Due to the direct relationship between power density and torque, maximum power density amount also will occur in this ratio.

\subsection{Back EMF}

The flux per pole in the proposed AFPM motor is given by:

$$
\Phi_{\text {pole }}=\alpha_{\mathrm{i}} \pi\left(r_{\text {out }}^{2}-r_{\text {in }}^{2}\right) \frac{B_{\max }}{2 p}
$$

Where, $\alpha_{\mathrm{i}}$ is the magnetic-field factor in the air-gap (in sinusoidal wave $\alpha_{\mathrm{i}}=2 / \pi$ ).

The RMS value of the induced $E M F$ in each phase, $E_{f}$, is equal to:

$$
E_{f}=\sqrt{2} \pi n_{\mathrm{s}} N_{\mathrm{ph}} k_{\mathrm{w}} B_{\max } \frac{\left(r_{\mathrm{out}}^{2}-r_{\mathrm{in}}^{2}\right)}{2}
$$

Where, $n_{\mathrm{s}}$ is the number of cycles per second and $k_{\mathrm{w}}$ is the winding factor. 


\subsection{Air-Gap Flux Linkage and Flux Density}

The air-gap flux linkage, $\Phi_{g}$, is generally defined as:

$$
\Phi_{g}=\sqrt{\left(\Phi_{m}+L_{d} I_{d}\right)^{2}+\left(L_{q} I_{q}\right)^{2}}
$$

where, $\Phi_{m}$ is the flux that provided with permanent magnets, and $L_{d}$ and $L_{q}$ are machine's $d$ and $q$-axis inductances respectively. Hence $L_{d} I_{d}$ and $L_{q} I_{q}$ are fluxes produced by the stator's $d$ and $q$-axis currents [9]. The air-gap flux linkage is given by the following equation:

$$
\Phi_{g}=k_{\mathrm{w}} N_{\mathrm{ph}} B_{g} 2\left(r_{\text {out }}^{2}-r_{\text {in }}^{2}\right)
$$

Where, $B_{g}$ is the air-gap flux density and is defined as:

$$
B_{g}=\sqrt{\left(B+B_{d}\right)^{2}+B_{q}^{2}}
$$

Where $B$ is the flux density produced by PMs. $B_{d}$ and $B_{q}$ are the total flux densities that provided with stator's $d$ and $q$-axis currents, respectively.

\section{OPTIMUM SIZING OF THE AFPM}

\subsection{Vehicle Characteristics}

Fuel economy characteristics (FEC) of a typical ICE often evaluated by the amount of fuel consumed per kWh of output energy. A typical FEC in a sample gasoline engine is shown in Fig. 6-a. The fuel consumption differs from one operation point to another. As shown in this figure, optimum operation points are very close to full load operation line. The engine speed is affected by fuel economy. The propose of HEV structure is making the possibilities for ICE to work in conditions close to the optimum operation points, to have lower fuel consumption.

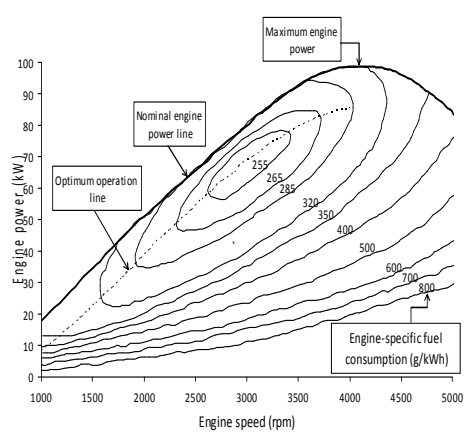

(a)
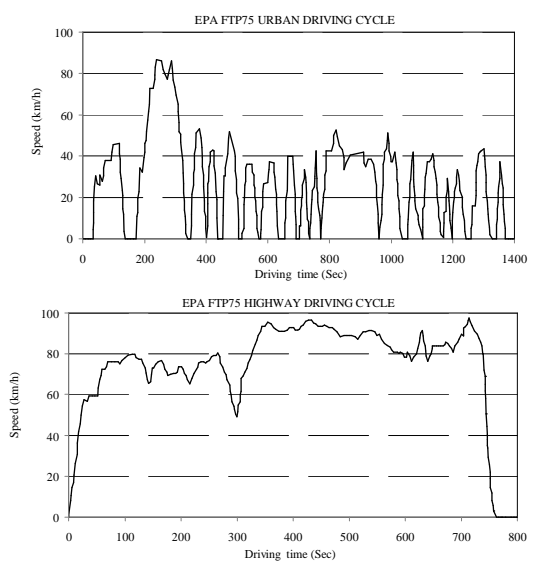

(b)

Fig 6 a) Fuel economy characteristics of a typical ICE, b) EPA FTP75 urban and highway drive cycles

To achieve the maximum efficiency of an ICE, the operating point should be close to the optimum operation line (shown in fig. 6-a) in various conditions. Considering that the amount of energy consumption of each vehicle in a time interval varied based on the type of speed characteristics, some standard cycles are presented. Having the same test routine, these standard cycles are used in different structures of vehicles. Fig. 6-b shows the urban and highway drive cycles of EPA FTP75.

\subsection{HEV Operating Modes}

Under normal conditions, the operating modes of a hybrid car can be defined as the following four conditions [2]:

1) Low power: In this mode the use of ICE reduce the overall efficiency. Therefore, electric motor and electrical energy stored in the battery is responsible for providing power requirements.

2) Medium power: In this operation mode ICE provides power requirements of $\mathrm{HEV}$, and some of this power can also be used to charge the battery.

3) High power: When there is a need to high power such as acceleration or hill climbing, the required power is supplied from ICE and electrical machine simultaneously.

4) Regeneration: During deceleration or braking, the battery is recharged by energy returned from the wheels, where the ICE is off.

\subsection{Multiple Speed Design Method for Electric}

\section{Machine used in HEV}

In any driving cycle, there would be some intermediate modes. In these modes different proportions of the required power, provided by the ICE and/or electric machine, can be determined continuously in all of the vehicle operation 
conditions. But to implement the design idea in a simple way, only above mentioned four operation modes are used.

Vehicles cycle efficiency, $\eta_{\mathrm{cV}}$, can be defined as:

$$
\eta_{\mathrm{cV}}=\frac{\sum_{\mathrm{k}=1}^{4} t_{\mathrm{k}}\left[\alpha_{\mathrm{k}} \eta_{\mathrm{Ik}}+\left(1-\alpha_{\mathrm{k}}\right) \eta_{\mathrm{Ek}}\right]}{T}
$$

Where $t_{\mathrm{k}}, \eta_{\mathrm{Ik}}, \eta_{\mathrm{Ek}}$ and $\mathrm{T}$ are time interval, ICE efficiency and electric machine efficiency, all in the operating mode $\mathrm{k}$ and the overall cycle time respectively. $\alpha_{\mathrm{k}}$ is the utilization coefficient of the ICE in the operating mode $\mathrm{k}$. The value of $\alpha_{\mathrm{k}}$ is between 0 and 1. $\alpha_{\mathrm{k}}=0$ means that the ICE is offline in the operating mode $\mathrm{k}$ and the total power required for $\mathrm{HEV}$ is provided only by the electric machine as a motor. The aim of the proposed design procedure is to maximize the amount of $\eta_{\mathrm{cV}}$.

To find out the improved operating point of HEV, the ICE efficiency at various speeds must be evaluated. Due to various types of ICEs, finding the improved operation point would be strongly depending on the type of ICE. In this paper to evaluate the performance of the proposed design method, fig. 6-a is used as a typical FEC. Considering that it is possible to use ICE at various speeds during a standard duty cycle, the operating point of ICE at the specified and considered speed must be chosen on the optimum operation line (OLL) of ICE. Using the operating point on this line, the efficiency of the ICE $\left(\eta_{\mathrm{I}}\right)$ in each mode maximizes. Therefore, to find the maximum value of $\eta_{\mathrm{cV}}$, the appropriate $\alpha_{\mathrm{k}}$ to achieve the maximum efficiency of the electric machine, must be determined. With this choice, the ICE is at maximum efficiency condition, and minimum fuel consumption will be occurs.

When vehicle needs the power more than the efficient ICE supplied power, the extra required power would be supplied by the electric machine (in the motoring mode). Therefore bidirectional power electronic converter delivers stored electric energy from batteries to electric machine. If the required power of HEV at considered speed becomes lower than the ICE supplied power on OLL, the ICE operate at optimum operating point. The extra ICE power directed to the electric machine which operates as a generator and the provided electric energy would be stored in the batteries.

Due to the HEV speed changes during any operating cycle, the purpose of this step is to determine $\alpha_{\mathrm{k}}$ and eventually $1-\alpha_{\mathrm{k}}$, in all the moments of driving cycle.
According to equation (16), if the amount of expression $\sum_{\mathrm{k}=1}^{4}\left(1-\alpha_{\mathrm{k}}\right) \eta_{\mathrm{Ek}}$ could be maximized, the $\eta_{\mathrm{cV}}$ will have its maximum value. Therefore the total distance traveled by the vehicle, using a specified battery charge and fuel, will be increased.

Fig. 7 shows the normalized efficiency curves of two design methods; SSD and MSD. In this figure, $\alpha_{\mathrm{k}}=0$ is considered, for the entire cycle. For simplicity, the vehicle speed is considered constant. The electric machine speed range in this simple curve has been considered between 0 to $1000 \mathrm{rpm}$.

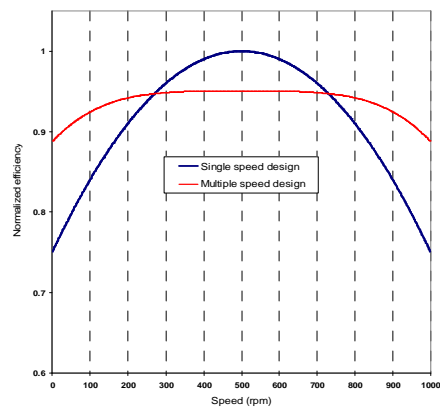

Fig 7 Normalized efficiency curves obtained from two methods; SSD and MSD

Fig. 7 shows that the maximum efficiency of the SSD based designed machine occurs at the nominal speed $(500 \mathrm{rpm}$ in this example). This maximum value in the normalized condition has been reached to the unit. This value is higher than the maximum value obtained using the MSD method. Conversely, the amount of $\eta_{\mathrm{cV}}$, in the MSD method is higher than that of the SSD method.

\subsection{Optimum Design of Afpm used for HEV}

Some constraints, such as flux saturation, type of structure, thermal constraints, limited available space in the vehicle wheel, various PMs inherent specifications, maximum current density of used conductor, and the driving voltage, should be considered to achieve required specifications in the proposed motor design. In other words, the motor optimization method is a multifunctional scheme and with this method the requested in-wheel motor is designed and analyzed.

To achieve the requested driving voltage and to induce the larger back electromotive force to the windings, the stator coils are independently wired on stator poles and are grouped into needed phases. With this method the higher motor speed is achieved and multiphase machine structures can be constructed. Therefore, the effects of the number of phases can be studied on the machine total efficiency. Other specifications of the motor are listed in Table 1. 
To introduce the size and characteristics of vehicle tire, the phrase $\mathrm{P} w w w / h h \mathrm{R} d d$ is used. In this expression, $\mathrm{P}$ and $\mathrm{R}$ denote passenger tire and radial tire, respectively, $w w w$ is the tire width in $\mathrm{mm}, h h$, as a percentage of $w w w$, is the height of the side wall, and $d d$ is the inside diameter in inches. In this application the tire size of P205/50R17 is selected to use in vehicle. The outside circumference of this tire is assumed about $2 \mathrm{~m}$.

Table 1 Specification of direct-drive electric wheel motor

\begin{tabular}{|l|l|}
\hline \hline Objectives & low speed, high torque \\
\hline Rated torque & $>30 \mathrm{Nm}$ at $420 \mathrm{rpm}$ \\
Max. torque & $>60 \mathrm{Nm}$ at $130 \mathrm{rpm}$ \\
Rated power & $3 \mathrm{~kW}$ \\
Rated speed & $420 \mathrm{rpm}$ \\
Vehicle max. speed & $50 \mathrm{~km} / \mathrm{hr}$ \\
Acceleration & $5 \mathrm{~seconds}$ for $20 \mathrm{~m} / \mathrm{sec}$ \\
Driving slope & $>8^{\circ}$ at $15 \mathrm{~km} / \mathrm{hr}$ \\
Motor weight & $<15 \mathrm{~kg}$ \\
Operation temp. range & $0^{\circ} \mathrm{C} \sim 40^{\circ} \mathrm{C}$ \\
\hline
\end{tabular}

There are some important parameters that affect the design of AFPMs. In these parameters the diameter ratio, $D_{i} / D_{o}$, and airgap flux density are the two design variables having more effect on the machine inherent characteristics. Therefore, in order to find the best performance of the desired AFPM and the machine's optimum size, the diameter ratio and air-gap flux density must be designated intently [17, 18]. The maximum motor efficiency is occurred at the maximum power density. To achieve the maximum power density of the machine and to determine design features many different structures must be analyzed. In this paper a software package is used for FEM method that enables analysis and optimization to do faster, more effective and simple. This software is an excellent supplement to analytical methods, especially when considering geometry details and variations in the machine construction. In this programming method a multifunctional optimization method is used to search the optimal values of the design variables that maximize the performance indices such as motor torque, torque or power density and overall efficiency. Design constraints for a HEV application are also included in the program. Also desired performance indices are weighted under the constraints, to achieve better compromise among the design variables.

Fig. 5 shows the normalized electromagnetic torque $\left(T_{\mathrm{em}} / T_{\mathrm{em}, \max }\right)$ variation as a function diameter ratio $\left(K_{\mathrm{D}}\right)$ for the AFPMs as equation (9) and (10).

The optimal design motor parameters and its technical data obtained from two design method (SSD and MSD) are presented in Table 2 . The nine coils are independently wired on stator poles at this machine. Three coils are connected to form each phase winding. Further studies by the finite element method need to be performed to get the final decision.

Table 2 Motor characteristic obtained from magnetic analysis and optimization

\begin{tabular}{|l|c|c|}
\hline \hline parameter & $\begin{array}{c}\text { From } \\
\text { SSD }\end{array}$ & $\begin{array}{c}\text { From } \\
\text { MSD }\end{array}$ \\
\hline Max. current per phase (A) & 19.6 & 20.4 \\
Rated torque (Nm) & 35.8 & 38.1 \\
Max. torque (Nm) & 75 & 75 \\
Flux density (T) & 0.9 & 0.8 \\
Motor weight (kg) (approximate) & 14.9 & 16.5 \\
Rated voltage (V) (with converter) & 48 & 48 \\
Max. torque density (Nm/kg) & 5.1 & 4.5 \\
Total air gap length (mm) & 2 & 2 \\
Number of rotor poles (on each & 12 & 12 \\
side) & 9 & 9 \\
Number of stator coils & 0.66 & 0.57 \\
$K_{\mathrm{D}}$ & 22.5 & 24.5 \\
Outer diameter (cm) & 15 & 14 \\
Inner diameter (cm)
\end{tabular}

\section{LOSS CALCULATION}

One limiting parameter in the machine design process is the power losses. The loss calculations are briefly described as follows $[11,13]$ :

1. The main losses in this electrical machine are rotational losses. These losses (also named as air friction losses) are dependent on air-gap length $(g)$ and outer diameter $\left(D_{\mathrm{o}}\right)$. The mechanical power needed to overcome the drag resistance of a rotating disc is:

$$
P_{\text {mech }}=0.0311 \times\left(\frac{2 g \times 10^{-3}}{D_{\mathrm{o}}}\right)^{-0.25} \eta^{-0.25} \rho^{0.75}\left(\frac{2 f}{p}\right)^{2.75}\left(\frac{D_{\mathrm{o}}}{2}\right)^{4.5}
$$

Where, $\eta$ and $\rho$ are the efficiency and air density, respectively and $f$ is the frequency of rotor.

2. Stator winding losses in the specific current $(I)$ are obtained by (18):

$$
P_{\mathrm{cu}}=R_{\mathrm{s}} I^{2}
$$

Where, $R_{s}$ is the stator winding resistance.

3. The magnetic field frequency causes additional losses in the stator conductors (winding eddy-current losses):

$$
P_{\text {eddy }-\mathrm{cu}}=\frac{\left(2 \pi f B_{\max } D_{\text {strand }} \times 10^{-3}\right)^{2}}{32 \times \rho_{\mathrm{cu}}} \times V_{\mathrm{cu}}
$$


where, $D_{\text {strand }}, \rho_{\text {cu }}$ and $V_{\text {cu }}$ are the diameter of each wire of conductor, electrical resistivity and volume of copper (winding), respectively.

In order to calculate the spinning loss with described equations the machine was operated using an uncut steel toroid core as the stator piece [4]. If the effects of stator slotting are to be considered the total core loss in the iron cored stator is more increased. But with a coreless stator this loss is neglected and the total efficiency is increased as shown in Tables 3 and 4.

\section{PROTOTYPE AND EXPERIMENTAL}

\section{VALIDATION}

The AFPM machine is modeled by using quasi-3D finiteelement method (FEM). The prototype motor based on the designs previously discussed have been fabricated and tested as illustrated in figures. The stator coils, rotor and their assembly are shown in fig. 8. The total losses calculation results of the designed machine with two design method are presented in Table 3. It can be shown that for this in-wheel drive in the electric vehicles, the coreless TORUS-NS AFPM designed by MSD method produces about $10 \%$ higher vehicles cycle efficiency when compared to SSD designed AFPM with the same characteristics. The validation of design method confirmed a good agreement between the measurements and results obtained by FEM (FLUX-3D and ANSYS) from a coreless AFPM prototype.

Table 3 Comparison of Obtained Results for Coreless AFPM with Two Design Methods in the Total HEV Operation Cycle

\begin{tabular}{|c|c|c|c|}
\hline \hline \multirow{2}{*}{ Parameter } & \multicolumn{2}{|c|}{ FEM results } & $\begin{array}{c}\text { Experimental } \\
\text { results }\end{array}$ \\
\cline { 2 - 4 } & $\begin{array}{c}\text { From } \\
\text { SSD }\end{array}$ & $\begin{array}{c}\text { From } \\
\text { MSD }\end{array}$ & $\begin{array}{c}\text { From } \\
\text { MSD }\end{array}$ \\
\hline \hline $\begin{array}{c}\text { Rated output } \\
\text { torque at rated } \\
\text { speed (Nm) }\end{array}$ & 37.8 & 38.1 & 37.2 \\
\hline $\begin{array}{c}\text { Max. Machine } \\
\text { Efficiency (\%) }\end{array}$ & 94.6 & 89.6 & 83.3 \\
\hline $\begin{array}{c}\text { Min. Machine } \\
\text { Efficiency (\%) }\end{array}$ & 45.4 & 65.3 & 59.7 \\
\hline $\begin{array}{c}\text { Vehicles cycle } \\
\text { efficiency, } \eta_{\mathrm{cv}}(\%)\end{array}$ & 39.2 & 48.7 & 47.0 \\
\hline \hline
\end{tabular}

Table 4 Comparison of Obtained Results for an AFPM with Coreless and Iron Core Stator both Designed by Proposed MSD Method

\begin{tabular}{|c|c|c|c|}
\hline \hline \multirow{3}{*}{ Parameter } & \multicolumn{2}{|c|}{ FEM results } & $\begin{array}{c}\text { Experimental } \\
\text { results }\end{array}$ \\
\cline { 2 - 4 } & $\begin{array}{c}\text { Iron } \\
\text { core }\end{array}$ & $\begin{array}{c}\text { Coreless } \\
\text { stator }\end{array}$ & $\begin{array}{c}\text { Coreless } \\
\text { stator }\end{array}$ \\
\hline
\end{tabular}

\begin{tabular}{|c|c|c|c|}
\hline & stator & & \\
\hline \hline $\begin{array}{c}\text { Rated output } \\
\text { torque at rated } \\
\text { speed (Nm) }\end{array}$ & 43.4 & 38.1 & 34.4 \\
\hline $\begin{array}{c}\text { Total machine } \\
\text { loss (W) }\end{array}$ & 381.7 & 310.5 & 404.0 \\
\hline $\begin{array}{c}\text { Machine } \\
\text { Efficiency } \\
(\%)\end{array}$ & 87.3 & 89.6 & 86.5 \\
\hline \hline
\end{tabular}

\section{CONCLUSIONS}

The characteristic equations for the design and to find the improved sizing for the best output power, have been obtained in this article. The electromagnetic design has been performed by applying the characteristic equations to the type of AFPM machine. In order to optimize the machine structure, the diameter ratio and the air-gap flux density have been chosen carefully. The all types of AFPM machines has been studied and investigated to choose the best structure for the intended application. A new design method based upon multi speed design strategy has been proposed. Using this Multi-Speed Design (MSD) method with a coreless type of stators, the total AFPM machine efficiency at the HEV operation cycles could be improved. The machines have been compared in terms of the power density and the results have been applied for this machine design method. The performance analysis of this axial flux permanent magnet in-wheel machine is done using finite-element method and the obtained test results validate the effectiveness of this proposed design method. The simulated and test results show that the coreless in-wheel direct drive AFPM designed by MSD method has a better efficiency and no cogging torque when compared with an AFPM with iron cored stator.
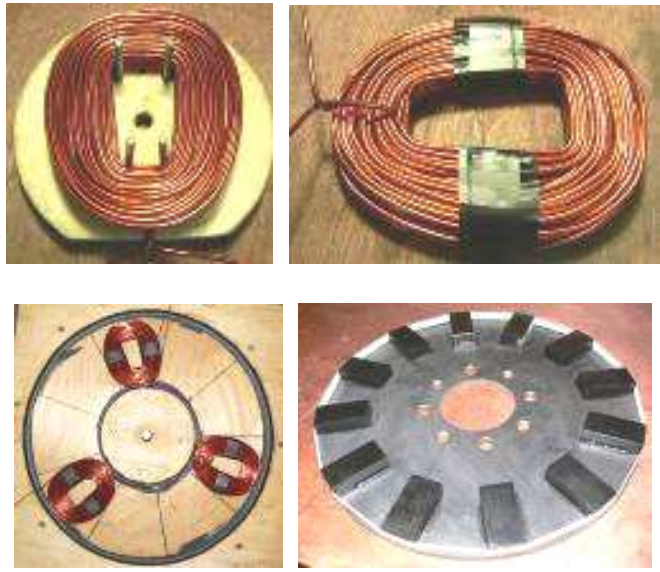

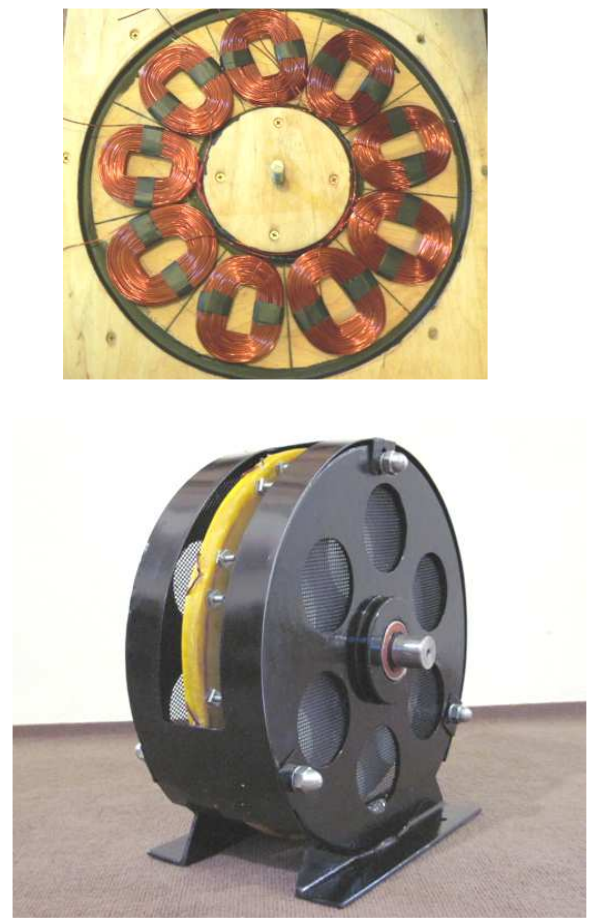

Fig 8 Stator, rotor and motor assembly

\section{REFERENCES}

[1]. F. Profumo, Z. Zhang, and A. Tenconi, "Axial Flux Machines Drives: A New Viable Solution for Electric Cars," IEEE Trans. Ind. Electron., Vol. 44, No. 1, pp. 39-45, Feb. 1997.

[2]. S. C. Oh, and A. Emadi, "Test and Simulation of Axial Flux-Motor Characteristics for Hybrid Electric Vehicles," IEEE Trans. Veh. Technol., Vol. 53, No. 3, pp. 912-919, May. 2004.

[3]. S. Huang, J. Luo, F. Leonardi, and T. A. Lipo, "A Comparison of Power Density for Axial Flux Machines Based on General Purpose Sizing Equations," IEEE Trans. Energy Convers., Vol. 14, No. 2, pp. 185-192, Jun. 1999.

[4]. A. Parviainen, M. Niemela, and J. Pyrhonen, "Modeling of Axial Flux Permanent-Magnet Machines," IEEE Trans. Ind. Appl. , Vol. 40, No. 5, pp. 1333-1340, Sep./Oct. 2004.

[5]. F. Locment, E. Semail, and F. Piriou, "Design and Study of a Multiphase Axial-Flux Machine," IEEE Trans. Magn., Vol. 42, No. 4, pp. 1427-1430, Apr. 2006.

[6]. T. F. Chan, L. L. Lai, and S. Xie, "Field Computation for an Axial Flux Permanent-Magnet Synchronous Generator," IEEE Trans. Energy Convers., Vol. 24, No. 1, pp. 1-11, Mar. 2009.

[7]. M. Sadeghierad, A. Darabi, H. Lesani, and H. Monsef, "Rotor Yoke Thickness of Coreless High-Speed Axial-Flux Permanent Magnet Generator," IEEE Trans. Magn., Vol. 45, No. 4, pp. 2032-2037, Apr. 2009.

[8]. J. H. Choi, J. H. Kim, D. H. Kim, and Y. S. Baek, "Design and Parametric Analysis of Axial Flux PM Motors With Minimized Cogging Torque," IEEE Trans. Magn., Vol. 45, No. 6, pp. 2855-2858, Jun. 2009.

[9]. T. S. Kwon, S. K. Sul, L. Alberti, and N. Bianchi, "Design and Control of an Axial-Flux Machine for a Wide FluxWeakening Operation Region," IEEE Trans. Ind. Appl., Vol. 45, No. 4, pp. 1258-1266, Jul. 2009.

[10]. C. C. Chan, A. Bouscayrol, and K. Chen, "Electric, Hybrid, and Fuel-Cell Vehicles: Architectures and Modeling," IEEE Trans. Veh. Technol., Vol. 59, No. 2, pp. 589-598, Feb. 2010.

[11]. D. Kowal, P. Sergeant, L. Dupre, and A. V. Bossche, "Comparison of Nonoriented and Grain-Oriented Material in an Axial Flux Permanent-Magnet Machine," IEEE Trans. Magn., Vol. 46, No. 2, pp. 279-285, Feb. 2010.

[12]. S. Javadi, and M. Mirsalim, "Design and Analysis of 42V Coreless Axial-Flux Permanent-Magnet Generators for Automotive Applications," IEEE Trans. Magn., Vol. 46, No. 4, pp. 1015-1023, Apr. 2010.

[13]. P. Zheng, J. Zhao, R. Liu, C. Tong, and Q. Wu, "Magnetic Characteristics Investigation of an Axial-Axial Flux Compound-Structure PMSM Used for HEVs," IEEE Trans. Magn., Vol. 46, No. 6, pp. 2191-2194, Jun. 2010.

[14]. J. F. Gieras, R. J. Wang, and M. J. Kamper, "Axial Flux Permanent Magnet Brushless Machines," Springer Science, Kluwer Academic Publishers, 2005.

[15]. Y. P. Yang and D. S. Chuang, "Optimal Design and Control of a Wheel Motor for Electric Passenger Cars," IEEE Trans. Magn., Vol. 43, No. 1, pp. 51-61, Jan. 2007.

[16]. C. Liu, K. T. Chau, and J. Z. Jiang, "A PermanentMagnet Hybrid Brushless Integrated Starter-Generator for Hybrid Electric Vehicles," IEEE Trans. Ind. Electron., Vol. 57, No. 12, pp. 4055-4064, Dec. 2010.

[17]. S. L. Ho, S. Niu, and W. N. Fu, "Design and Analysis of a Novel Axial-Flux Electric Machine," IEEE Trans. Magn., Vol. 47, No. 10, pp. 4368-4371, Oct. 2011.

[18]. A. J. Rix, and M. J. Kamper, "Radial-Flux PermanentMagnet Hub Drives: A Comparison Based on Stator and Rotor Topologies," IEEE Trans. Ind. Electron., Vol. 59, No. 6, pp. 2475-2483, Jun. 2012.

[19]. J. F. Gieras, R. J. Wang, and M. J. Kamper, "Axial-flux Permanent Magnet Machines," Dordrecht: Kluwer Academic Publishers, 2004.

[20]. J. F. Gieras and M. Wing, "Permanent Magnet Motor Technology, Design and Applications," New York: Marcel Dekker Inc, 1997.

[21]. P. Campbell, "Principles of a Permanent-Magnet AxialField D.C. Machine," Proceedings of the IEE, Vol. 121, No. 12, pp. 1489-1494, 1974.

[22]. F. Carrichi, F. Crescimbini and O. Honorati, "Low-Cost Compact Permanent Magnet Machine for Adjustable-Speed Pump Application," IEEE Trans. Ind. Appl., Vol. 34, No. 1, pp. 109-116, 1998.

[23]. S. Huang, M. Aydin and T. A. Lipo, "TORUS Concept Machines: Pre-Prototyping Design Assessment for Two Major Topologies," In Proceedings of IEEE Industry Applications 
Conference, Thirty-Sixth IAS Annual Meeting. Vol. 3, p. 1619-1625, 2001

[24]. V.A. Lavrinovich, A.V. Lavrinovich and A.V. Mytnikov, "Development of Advanced Control State Technology of Transformer and Electric Motor Windings Based on Pulsed Method," International Journal on Technical and Physical Problems of Engineering (IJTPE), Issue. 13, Vol. 4, No. 4, pp. 149-153, Dec. 2012.

[25]. H. Hatami, M. B. B. Sharifian, M. R. Feyzi and M. Sabahi, "Analysis and Improved Design of Direct-Drive Coreless AFPM In-Wheel Machine for HEV Application," International Journal on Technical and Physical Problems of Engineering (IJTPE), Issue. 15, Vol. 5, No. 2, pp. 161-166, Jun. 2013.

\section{BIOGRAPHIES}

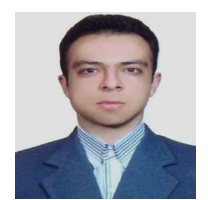

Hojat Hatami was born in Orumie, Iran, in 1981. He received his B.Sc. and M.Sc. degrees in Electrical Engineering in 2005 and 2008 both from University of Tabriz, Tabriz, Iran, where he is currently studying towards his $\mathrm{PhD}$ degree. His employment experience included three years of cooperation with Engineering Studies Department of MONA Consultants Company in some regional projects of eastern Azarbayjan state in Iran. He is currently working as a lecturer at Electrical Engineering Department of Seraj Higher Educational Institute (SHEI), Tabriz, Iran. He has published some technical papers in the national and international conferences. His special fields of interest included Electric Machines and Drives, Electric and hybrid vehicles, power electronics and power quality and nowadays he is working on Electric Machines branch.

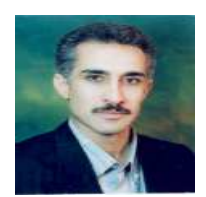

Mohammad Bagher Banae Sharifian Mohammad Bagher Bannae Sharifian received the B.Sc. and M.Sc. degrees in electrical power engineering, and the $\mathrm{Ph} . \mathrm{D}$. degree in electrical engineering from the University of Tabriz, Tabriz, Iran, in 1989, 1992, and 2000, respectively. In 1992, he was a Lecturer at the Department of Electrical Engineering, University of Tabriz. In 2000, he was a Professor at the Department of Electrical Power, Faculty of Electrical and Computer Engineering, University of Tabriz. His research interests include design, modeling and analysis of electrical machines, transformers, and electric and hybrid electric vehicle drives. He has published some technical papers in the national and international ISI journals and conferences.

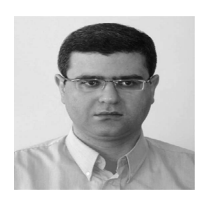

Mehran Sabahi was born in Tabriz, Iran, in 1968. He received the B.Sc. degree in electronic engineering from the University of Tabriz, Tabriz, Iran, the M.Sc. degree in electrical engineering from Tehran University,

Tehran, Iran, and the Ph.D. degree in electrical engineering from the University of Tabriz, in 1991, 1994, and 2009, respectively. In 2004, he joined the Faculty of Electrical and Computer Engineering, University of Tabriz, where he has been an Assistant Professor since 2009. His current research interests include power electronic converters and high frequency link power electronic transformers. 